\title{
Quantifying Hydrological Uncertainties under Climate Change using High-Resolution Numerical Models
}

\author{
Jorge Sebastian Moraga ${ }^{1}$, Nadav Peleg ${ }^{2}$, Peter Molnar ${ }^{1}$, Simone Fatichi $^{3}$, and Paolo \\ Burlando ${ }^{1}$ \\ ${ }^{1}$ ETH Zürich D-BAUG \\ ${ }^{2}$ University of Lausanne \\ ${ }^{3}$ National University of Singapore
}

January 27, 2022

\begin{abstract}
Modelling the response of hydrological processes to the changing climate requires the use of a chain of numerical models, each of which contributes some degree of uncertainty to the final outputs. As a result, hydrological projections, despite the progressive increase in the accuracy of the models along the chain, can still display high levels of uncertainty, especially at small temporal and spatial scales. The randomness intrinsic to climate phenomena, known as internal climate variability, is also a component contributing to the uncertainty of the hydrological projections. Unlike the uncertainties emerging from the climate and hydrological models, the internal climate variability is irreducible. In this work, we quantify and partition the uncertainty of hydrological processes in two mountainous catchments in Switzerland, emerging from climate models and internal variability, across a broad range of scales. To that end, we used high-resolution ensembles of climate and hydrological data, produced by a two-dimensional weather generator (AWE-GEN-2d) and a distributed hydrological model (Topkapi-ETH). We quantified the uncertainty in hydrological projections towards the end of the century through the estimation of the values of signal-to-noise ratios (STNR). We found small STNR values $(<-1)$ in the projection of annual streamflow for most sub-catchments in both study sites that are dominated by the large natural variability of precipitation (explains $\sim 70 \%$ of total uncertainty). Furthermore, we investigated in detail specific hydrological components that are critical in the model chain. For example, snowmelt or liquid precipitation exhibits robust change signals, which translates into high STNR values for streamflow during warm seasons and at higher elevations, together with a larger contribution of climate model uncertainty, suggesting that an improvement of the involved models has the potential of significantly narrowing the uncertainty. In contrast, extreme flows show low STNR values due to large internal climate variability across all elevations, which limits the possibility of narrowing their estimation uncertainty in a warming climate.
\end{abstract}

\section{Hosted file}

Hyd.Proc. Quantifying Hydrological Uncertainties.docx available at https://authorea.com/ users/321953/articles/554323-quantifying-hydrological-uncertainties-under-climatechange-using-high-resolution-numerical-models 

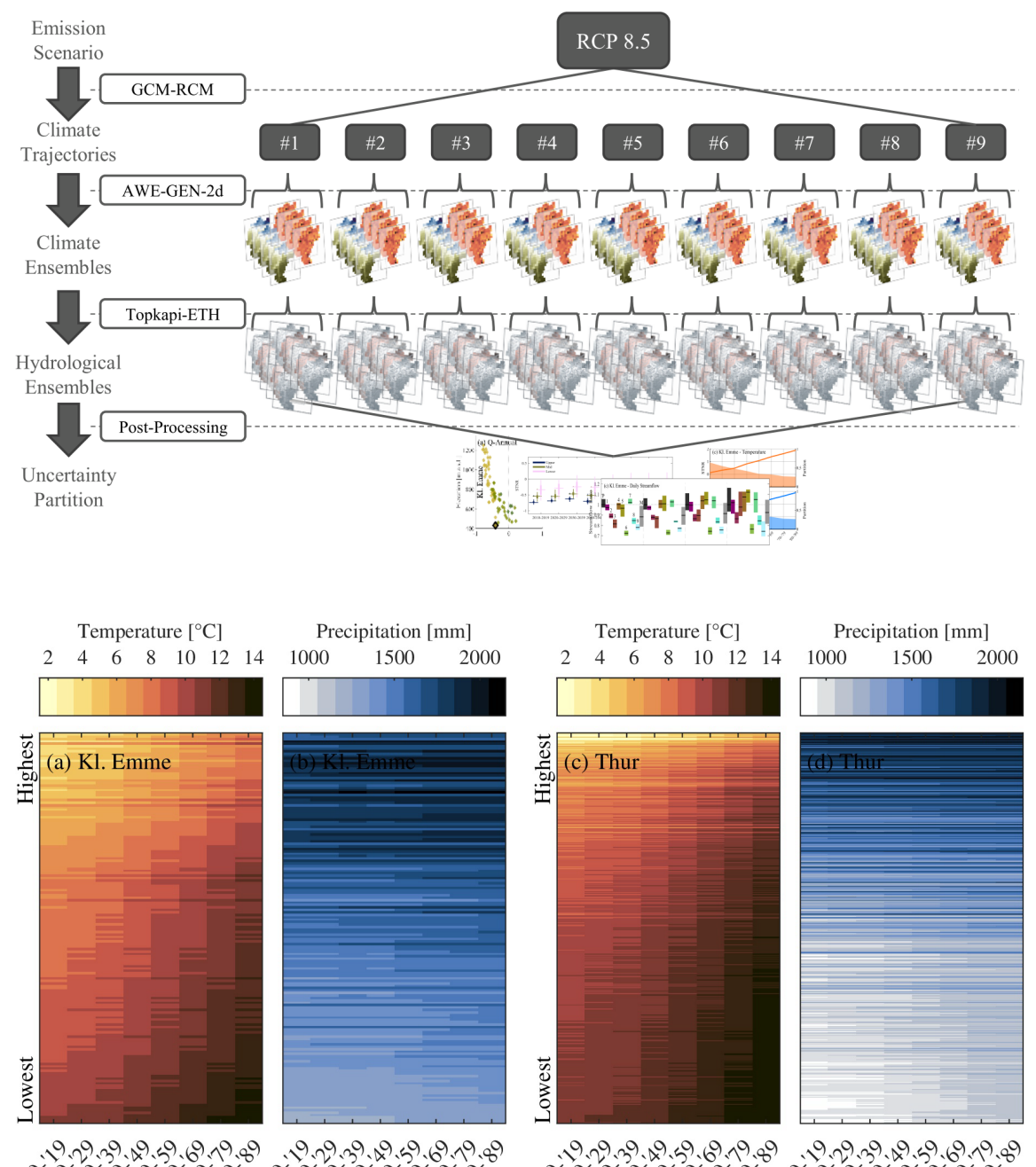

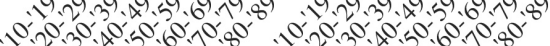
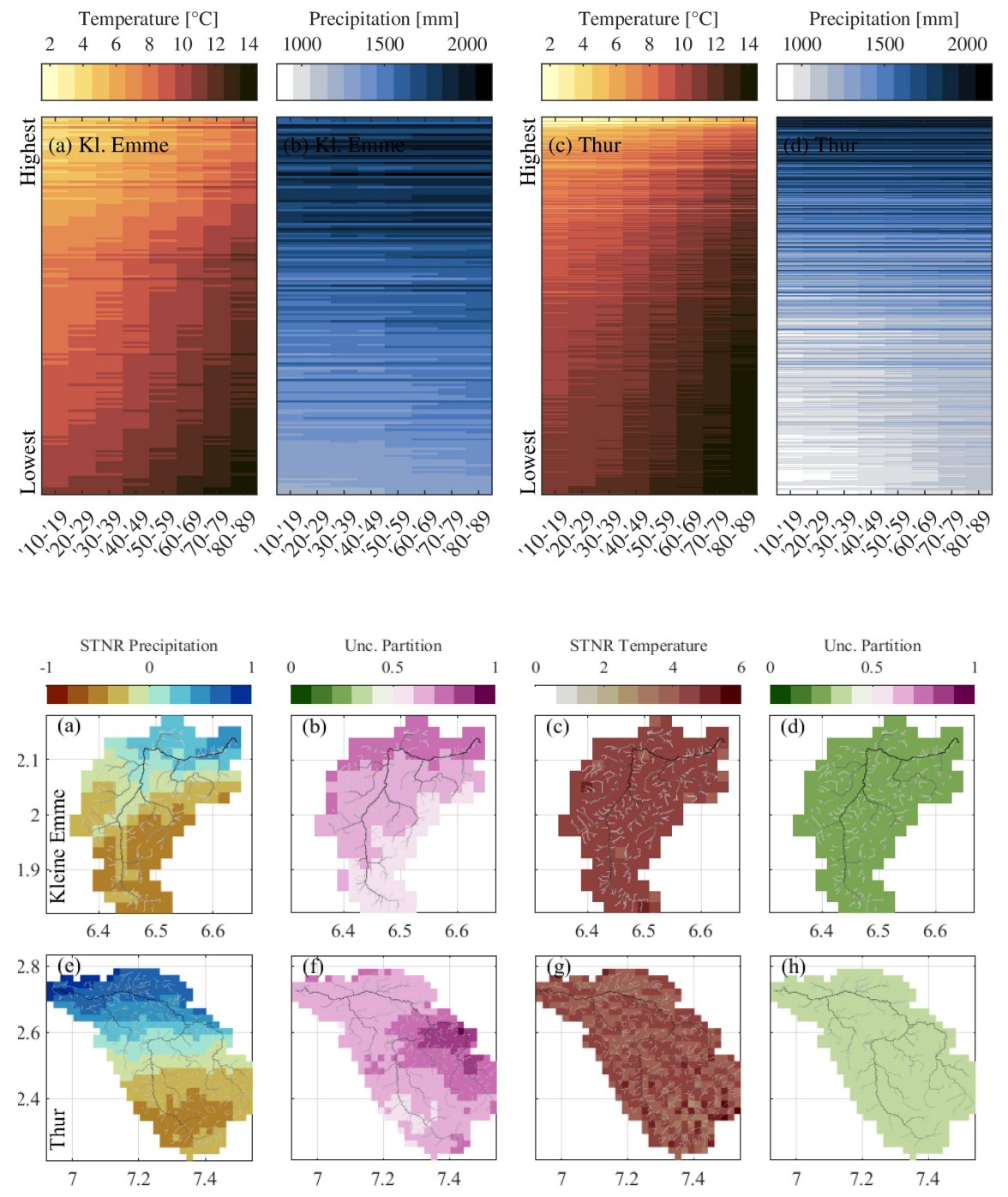

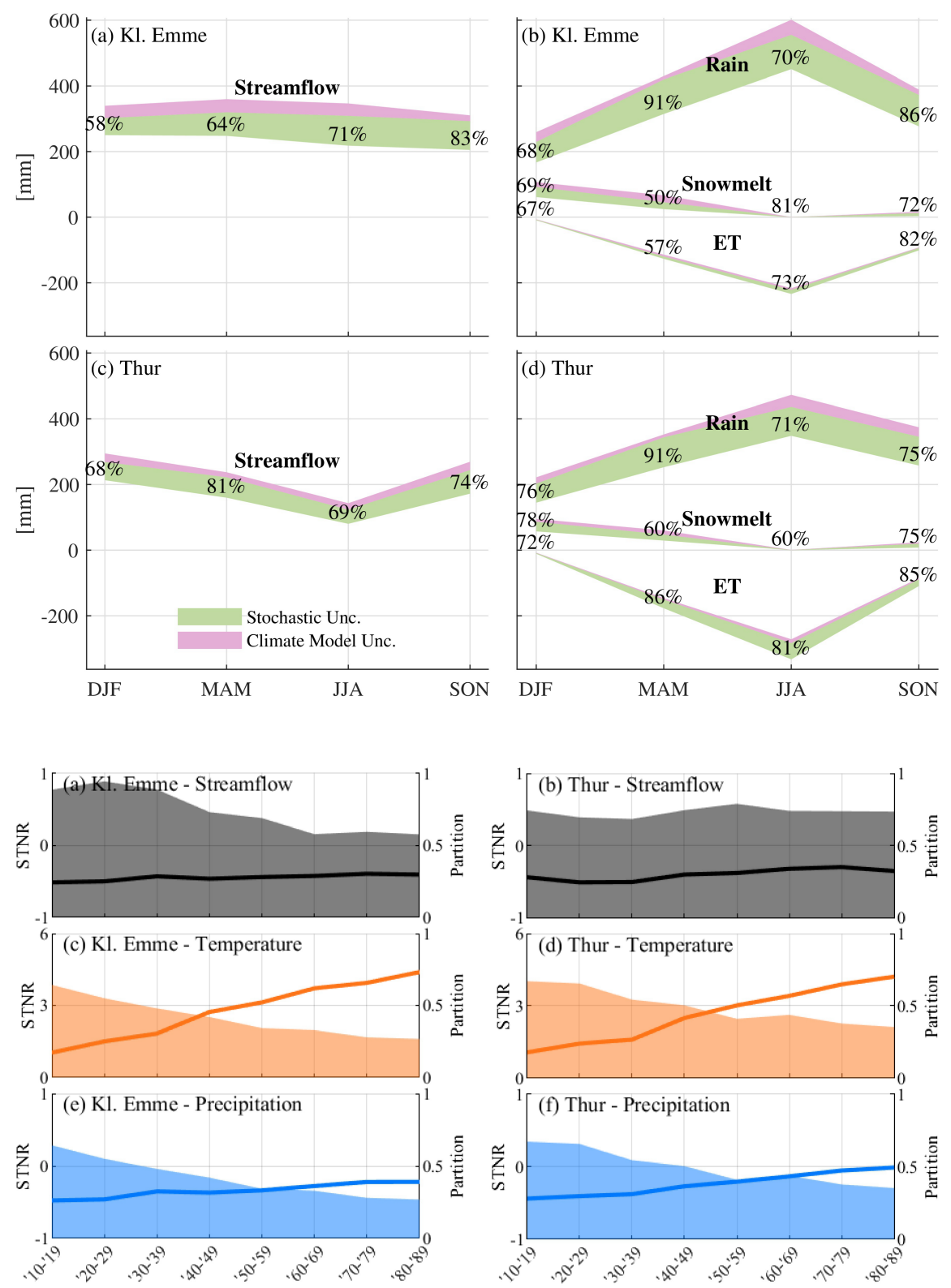

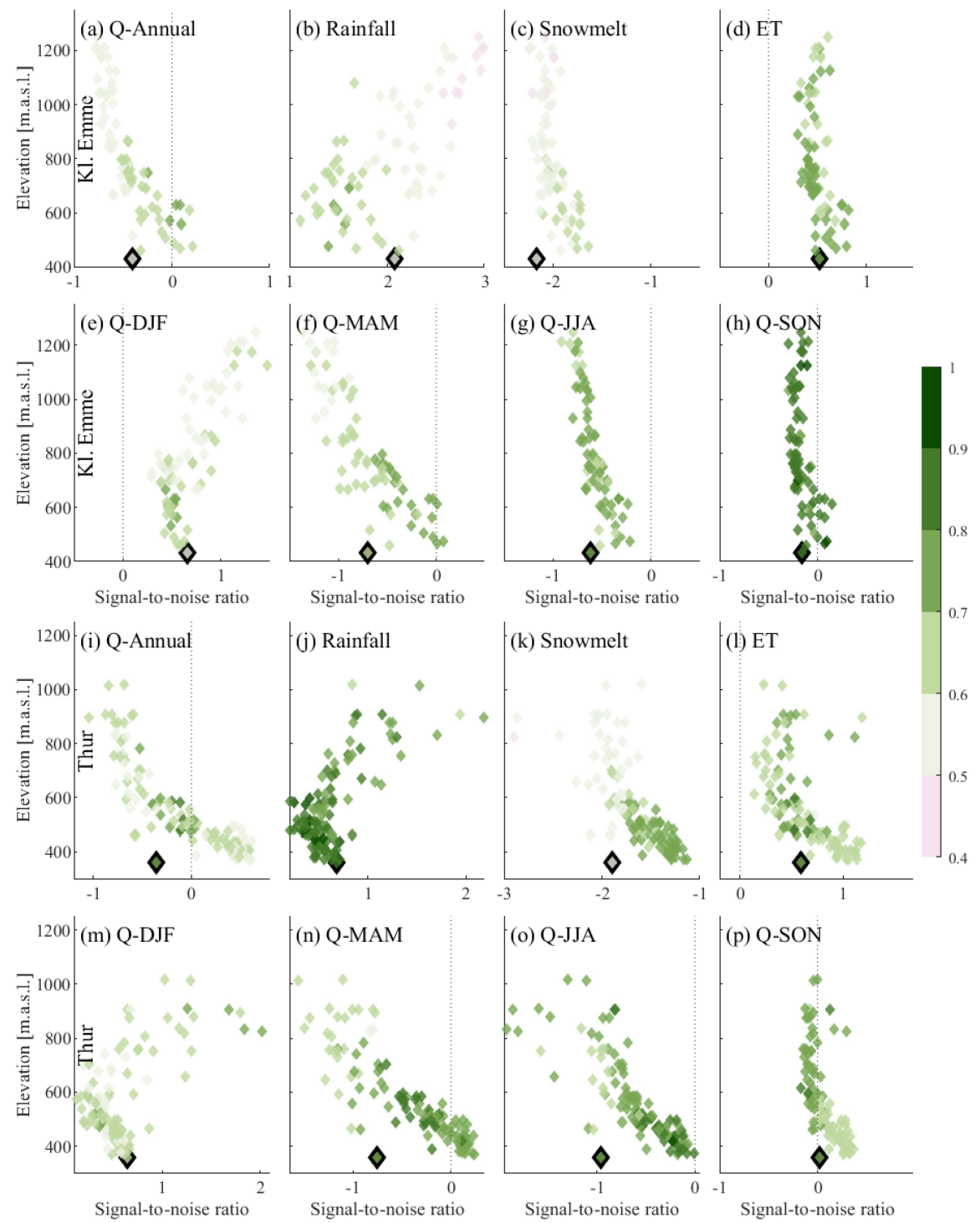

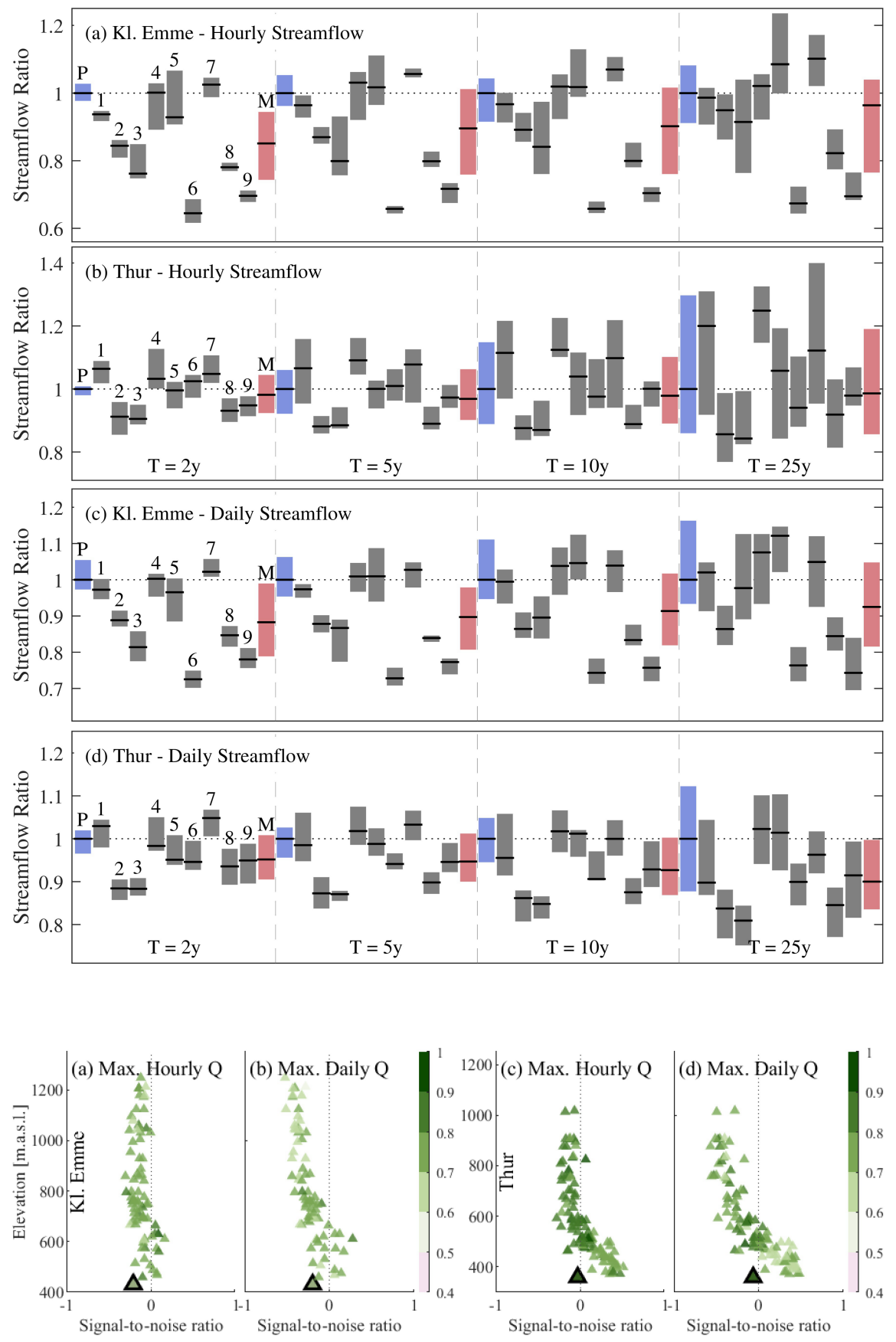